\title{
Comparison of three techniques of inhalation on the airway response to terbutaline
}

\author{
MJ CUSHLEY, RA LEWIS, AE TATTERSFIELD \\ From the University of Southampton Department of Medicine (I), Southampton General Hospital, \\ Southampton
}

ABSTRACT The relative efficiency of the metered dose inhaler (MDI), the MDI attached to a pear shaped extension tube (PET), and the Inspiron Mini-Neb nebuliser were assessed in eight normal and eight asthmatic subjects. Subjects inhaled the same increasing doses of terbutaline with each technique on different occasions and the response was measured as specific airway conductance

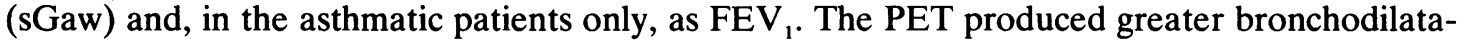
tion than either the MDI or the nebuliser in both normal and asthmatic subjects. Serum terbutaline concentrations were similar after the PET and MDI in the normal subjects, but were lower with the PET in the asthmatic patients. The nebuliser produced about the same amount of bronchodilatation as the MDI-slightly less in the normal subjects and slightly more when assessed as $\mathrm{FEV}_{1}$ in the asthmatic subjects. Serum terbutaline concentrations were lower after the nebuliser than after the MDI in both groups of subjects. For patients with moderately severe airways obstruction requiring large doses of beta agonist, the nebuliser will produce an amount of bronchodilatation similar to the MDI with lower blood levels. Overall, the PET produced greater bronchodilatation than either of the other two methods of inhalation, with low serum terbutaline concentrations similar to those produced by the nebuliser in the asthmatic patients.

Beta $_{2}$ adrenoceptor agonists are usually administered to patients with asthma by inhalation, since maximum bronchodilatation can be achieved rapidly with small doses and few systemic side effects. ${ }^{12}$ The pressurised metered dose inhaler (MDI) is the most convenient and widely used method of delivery. Less than $10 \%$ of the dose from an MDI reaches the airways, however, even with optimum use $^{34}$ and many patients are unable to use inhalers correctly despite adequate tuition. ${ }^{5}$ Extension tubes or spacers were designed to increase the proportion of the dose from an MDI reaching the airways and also to overcome the problems of poor inhaler technique. ${ }^{6}$ A pear shaped extension tube (PET) has been shown to decrease aerosol deposition in the mouth and oropharynx and to increase lung deposition. ${ }^{7}$

Beta agonists can also be inhaled via a nebuliser, a technique initially used for patients with severe

Address for reprint requests: Dr AE Tattersfield, Department of Medicine, Southampton General Hospital, Southampton SO9 4XY.

Accepted 26 September 1983 asthma in hospital, but now being recommended for use at home. ${ }^{8}$ The dose of beta agonist prescribed for nebulisation is up to 50 times as great as that from an MDI. It is not clear whether such large doses are recommended because of the severity of the asthma or because nebulisation is thought to be a less efficient means of administering a bronchodilator. It is important to clarify this, since if the techniques are of equal efficiency the large dose given in the nebuliser may be excessive when taken at home by a patient whose asthma is in remission.

This study was designed to determine the relative efficiency of the MDI, the MDI attached to a PET, and the Inspiron Mini-Neb nebuliser in achieving bronchodilatation with the $\beta$ adrenoceptor agonist terbutaline.

\section{Methods}

The study was carried out on eight normal, nonatopic subjects aged 22-36 years and eight asthmatic subjects aged 19-61 years. All were non-smokers and gave informed consent. The study was agreed by the Southampton ethical committee. All asthmatic 
Table 1 Clinical details of asthmatic patients

\begin{tabular}{|c|c|c|c|c|c|}
\hline \multirow{2}{*}{$\begin{array}{l}\text { Patient } \\
\text { No }\end{array}$} & \multirow{2}{*}{ Sex } & \multirow{2}{*}{$\begin{array}{l}\text { Age } \\
(y)\end{array}$} & \multicolumn{2}{|c|}{ Mean baseline $F E V_{1}$} & \multirow[t]{2}{*}{ Treatment* } \\
\hline & & & $l$ & $\%$ predicted & \\
\hline $\begin{array}{l}1 \\
2 \\
3 \\
4 \\
5 \\
6 \\
7 \\
8\end{array}$ & $\begin{array}{l}\mathbf{M} \\
\mathbf{M} \\
\mathbf{M} \\
\mathbf{F} \\
\mathbf{F} \\
\mathbf{M} \\
\mathbf{M} \\
\mathbf{M}\end{array}$ & $\begin{array}{l}30 \\
60 \\
60 \\
59 \\
19 \\
54 \\
59 \\
61\end{array}$ & $\begin{array}{l}3 \cdot 75 \\
1 \cdot 2 \\
1 \cdot 15 \\
1 \cdot 25 \\
1 \cdot 2 \\
1 \cdot 1 \\
1 \cdot 5 \\
1 \cdot 2\end{array}$ & $\begin{array}{l}75 \\
43 \\
35 \\
57 \\
38 \\
32 \\
50 \\
41\end{array}$ & $\begin{array}{l}\text { SCG, Sa } \\
\text { Sa, AmSR, Pred } 7.5 \mathrm{mg} \\
\text { Sa, B, Pred } 7.5 \mathrm{mg} \\
\text { Sa, B, Pred } 5 \mathrm{mg} \\
\text { Sa, B, AmSR, Pred } 5 \mathrm{mg} \\
\text { Sa, B, Ip, AmSR } \\
\text { Sa, B, AmSR, Pred } 5 \mathrm{mg} \\
\text { Sa, B, Ip, Pred } 5 \mathrm{mg}\end{array}$ \\
\hline
\end{tabular}

*Sa-salbutamol inhaler; SCG-sodium cromoglycate; AmSRaminophylline, slow release; $B$-beclomethasone dipropionate inhaler; Ip-ipratropium bromide inhaler; Pred-prednisolone.

subjects (six atopic, two non-atopic) showed an improvement in $\mathrm{FEV}_{1}$ of greater than $20 \%$ after $200 \mu \mathrm{g}$ of inhaled salbutamol. The baseline FEV was $32-75 \%$ of the predicted value (mean $46 \%$ ) and varied by less than $12 \%$ between study days. Bronchodilator drugs were discontinued 12 hours before each experiment; oral and inhaled corticosteroids were continued as usual. Details of individual asthmatic subjects are shown in table 1 .

Airway response was measured as specific airway conductance (sGaw) in a pressure compensated volume displacement body plethysmograph (Fenyves and Gut). Each measurement of sGaw was obtained as a mean value from 10 tracings recorded on light sensitive paper, coded and read blind by a single observer. $\mathrm{FEV}_{1}$, taken as the best of three attempts, was measured with a dry wedge spirometer, and heart rate by radial pulse palpation with the subject seated. Serum terbutaline levels were assayed by gas chromatography and mass spectrometry. ${ }^{9}$

\section{PROTOCOL}

Each subject attended on four occasions to inhale either terbutaline by one of the three techniques described below or placebo in random order.

Subjects rested for 10 minutes on arrival. Baseline measurements of heart rate, sGaw and, in the asthmatic subjects only, FEV , were carried out and repeated 10 minutes later. The subject then inhaled six doses of terbutaline at 15 minute intervals with doses increasing from $31 \mu \mathrm{g}$ to a cumulative dose of $4000 \mu \mathrm{g}(31,62,125,250,1000$, and 4000). Measurements of heart rate, sGaw, and $\mathrm{FEV}_{1}$ were made 15 minutes after each dose and followed immediately by the next dose. Ten millilitres of venous blood was withdrawn for terbutaline assay 45 minutes after the final dose in seven normal and six asthmatic subjects. (Specimens were broken in transit for one normal and two asthmatic subjects.)

\section{METHOD OF INHALATION}

(1) MDIs were specially prepared to administer 31 , $62,125,250$, and $1000 \mu \mathrm{g}$ terbutaline per actuation. Normal subjects were instructed on inhaler technique; asthmatic patients used their normal technique. (2) An MDI attached to a pear shaped extension tube (PET: vol 0.751 , length $22 \mathrm{~cm}$ ) was activated conventionally. Each dose was followed by two deep inhalations from the PET.

(3) Terbutaline respirator solution $(10 \mathrm{mg} / \mathrm{ml})$ was diluted in normal saline and inhaled from an Inspiron nebuliser driven by compressed air at $8 \mathrm{l} / \mathrm{min}$. Subjects wore a nose clip and inhaled via a face mask using tidal breathing. The dose of terbutaline was determined by weighing the nebuliser before and after five minutes' nebulisation. The concentration of terbutaline was adjusted so that the doses given over five minutes were the same as those given by the MDI.

(4) The placebo run consisted of three inhalations from an identical MDI containing propellant only,

Table 2 Mean baseline pulmonary function values (SEM in parentheses) with median maximum percentage change in specific airway conductance (sGaw) and FEV, from baseline and serum terbutaline concentrations after the four techniques of inhalation

\begin{tabular}{|c|c|c|c|c|c|c|c|c|c|}
\hline & & \multicolumn{2}{|l|}{ Placebo } & \multicolumn{2}{|c|}{$\begin{array}{l}\text { Metered dose inhaler } \\
(M D I)\end{array}$} & \multicolumn{2}{|c|}{$\begin{array}{l}\text { MDI with pear shaped } \\
\text { extension tube (PET) }\end{array}$} & \multicolumn{2}{|l|}{ Nebuliser } \\
\hline & & Mean & $\begin{array}{l}\text { Median } \\
\text { max \% } \\
\text { change }\end{array}$ & Mean & $\begin{array}{l}\text { Median } \\
\text { max \% } \\
\text { change }\end{array}$ & Mean & $\begin{array}{l}\text { Median } \\
\text { max \% } \\
\text { change }\end{array}$ & Mean & $\begin{array}{l}\text { Median } \\
\text { max \% } \\
\text { change }\end{array}$ \\
\hline $\begin{array}{l}\text { sGaw } \\
\quad\left(\mathbf{l s}^{-1} \mathbf{k P a}^{-1}\right) \\
\text { FEV (1) } \\
\text { Terbutaline } \\
\text { (ng/ml) }\end{array}$ & $\begin{array}{l}\text { Normal } \\
\text { Asthma } \\
\text { Asthma } \\
\text { Normal } \\
\text { Asthma }\end{array}$ & $\begin{array}{l}1.82(0.21) \\
0.67(0.10) \\
1.61(0.33)\end{array}$ & $\begin{array}{r}28 \\
4 \\
12\end{array}$ & $\begin{array}{l}1.76(0.18) \\
0.67(0.10) \\
1.62(0.30) \\
4.14(0.57) \\
3.54(0.73)\end{array}$ & $\begin{array}{l}45 \\
48 \\
26\end{array}$ & $\begin{array}{l}1.96(0.22) \\
0.65(0.10) \\
1.63(0.37) \\
3.64(0.55) \\
2.07 \dagger(0.21)\end{array}$ & $\begin{array}{l}61 \\
62 \\
46\end{array}$ & $\begin{array}{l}1.90(0.20) \\
0.73(0.13) \\
1.62(0.34) \\
1.71^{*}(0.24) \\
2.03 \ddagger(0.31)\end{array}$ & $\begin{array}{l}45 \\
47 \\
32\end{array}$ \\
\hline
\end{tabular}

*Significantly different from MDI and PET for normal subjects $(p<0.005)$.

†Significantly different from MDI for asthmatic subjects $(\mathrm{p}<0.05)$.

$\ddagger$ Significantly different from PET for normal subjects ( $p<0.05)$. 
followed by three inhalations from the nebuliser containing diluent only.

\section{ANALYSIS OF RESULTS}

Since the change in sGaw and $\mathrm{FEV}_{1}$ after terbutaline varied between subjects and was not normally distributed, we plotted log change in sGaw and $\mathrm{FEV}_{1}$ against $\log$ cumulative dose of terbutaline. Least mean square regressions were calculated for the data for all eight subjects for each technique and compared by an analysis of variance for slope and position. Heart rate response was compared with a two way analysis of variance, and terbutaline concentrations with Student's paired $t$ test within groups and unpaired $t$ test between groups.

\section{Results}

Mean baseline values for sGaw and $\mathrm{FEV}_{1}$ for the normal and asthmatic subjects did not differ significantly on the four study days (table 2 ). The administration of terbutaline by all three techniques produced a dose dependent increase in sGaw in both groups of subjects and a dose dependent increase in $\mathrm{FEV}_{1}$ in the asthmatic subjects (figs 1-3). Median maximum percentage increases from baseline were greatest with the PET, $61 \%$ for sGaw in the normal subjects and $62 \%$ and $46 \%$ for sGaw and $\mathrm{FEV}_{1}$ in the asthmatic subjects (table 2). The mean slopes of

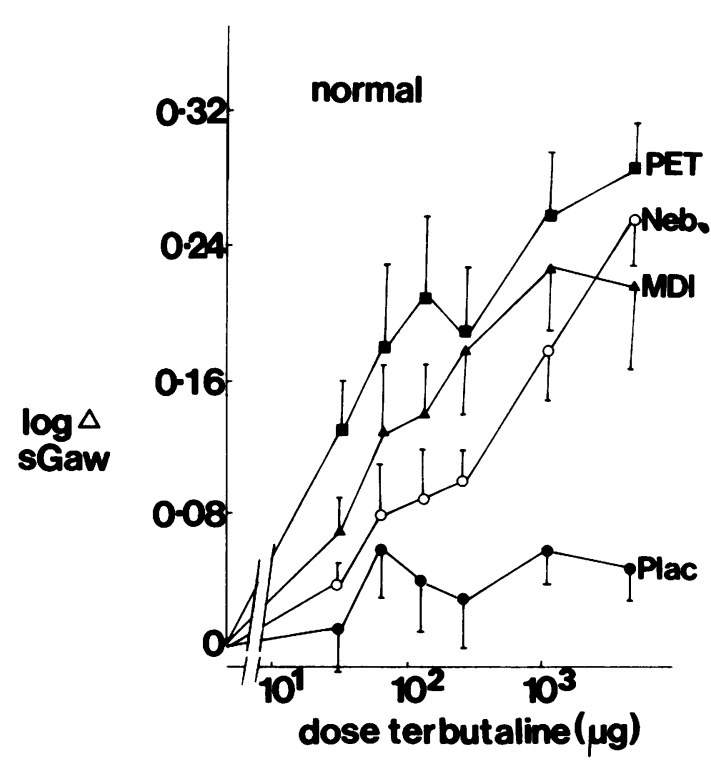

Fig 1 Response of specific airway conductance (sGaw) to the four techniques of inhalation in normal subjects. Each point represents the mean and SEM of the log change in sGaw from baseline for eight subjects.

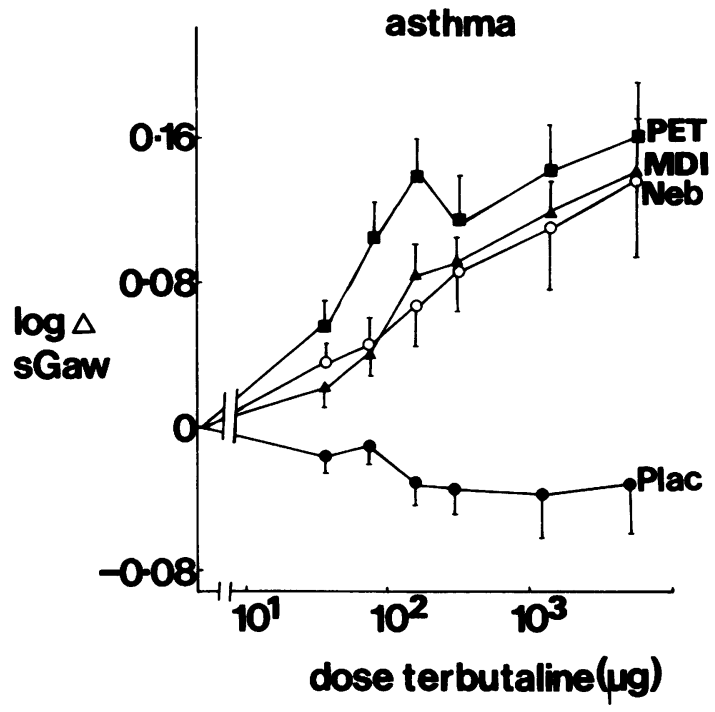

Fig 2 Response of specific airway conductance (sGaw) to the four techniques of inhalation in asthmatic subjects. Each point represents the mean and SEM of the log change in sGaw from baseline for eight subjects.

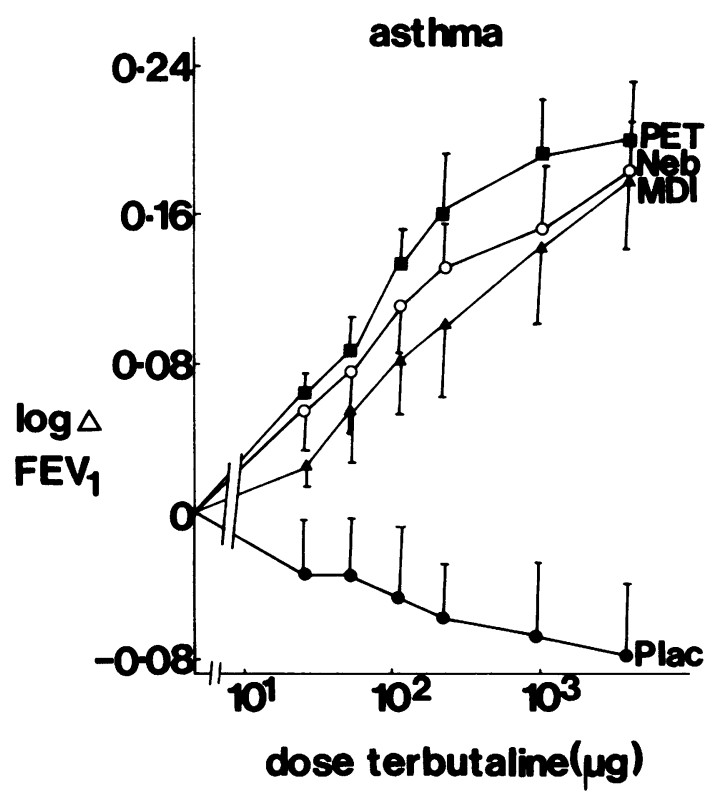

Fig 3 Response of $F E V$, to the four techniques of inhalation in asthmatic subjects. Each point represents the mean and SEM of the log change in FEV, from baseline for eight subjects. 
the $s G a w$ and $\mathrm{FEV}_{1}$ dose response curves for the three techniques did not differ significantly from parallel for either the normal or the asthmatic subjects $(p<0.05)$.

The use of the PET caused the terbutaline dose response curves to be displaced to the left compared with the other two techniques when assessed in terms of sGaw in both normal and asthmatic subjects $(p<0.005)$, and when assessed in terms of $\mathrm{FEV}_{1}$ in the asthmatic subjects $(\mathrm{p}<0.005)$.

In the normal subjects the dose response curve for the nebuliser was displaced to the right compared with that for the MDI $(p<0.025)$. In the asthmatic subjects there was no difference between the responses when assessed in terms of $s G a w$ ( $p>$ $0 \cdot 25$ ), but the nebuliser curve was displaced to the left of the MDI curve when assessed in terms of $\mathrm{FEV}_{1}(\mathrm{p}<0.01)$.

In normal subjects heart rate was slightly higher with MDI and PET (6 (SD 3) beats/min) than with nebuliser or placebo; the difference was significant for the last two doses (fig 4, $p<0.05$ ). In the asthmatic subjects heart rate tended to fall and did not differ with any technique.

In the normal subjects serum terbutaline concentrations after inhalation from the MDI and PET were similar $(4.1$ and $3.6 \mathrm{ng} / \mathrm{ml})$ and both were greater than the concentrations that followed the nebuliser $(1.7 \mathrm{ng} / \mathrm{ml}, \mathrm{p}<0.05)$. Terbutaline concentrations in the asthmatic subjects did not differ from those seen in the normal subjects after the MDI and nebuliser (3.5 and $2.0 \mathrm{ng} / \mathrm{ml}$ ), but were lower after the PET $(2 \cdot 1 \mathrm{ng} / \mathrm{ml}, \mathrm{p}<0.05)$ (table 2).

\section{Discussion}

Terbutaline dose response curves were constructed to allow comparison of three different modes of inhalation. The same dose of terbutaline was used with each technique to separate the effect of dosage from that of the method of administration.

Pharmacokinetic and direct deposition studies show that $80 \%$ of the dose from an MDI is impacted in the mouth and oropharynx to be subsequently swallowed. ${ }^{34}$ This is due to the high velocity and large size of droplets leaving the actuator. Extension tubes were designed to decrease the velocity of aerosol entering the mouth and reduce droplet size by allowing time for evaporation of propellant. ${ }^{6}$ Poor inhalation technique is also less important because the drug remains suspended in the extension tube for several seconds. The conical shape of the extension tube used in this study (PET) was designed to fit the shape of the aerosol cloud leaving the MDI, thus reducing drug impaction in the apparatus. In patients with airways obstruction the addition of this PET to an MDI reduced drug impaction in the mouth from $82 \%$ to $57 \%$ of the aerosol dose and increased lung deposition from $8 \%$ to $13 \% .^{7}$ Studies of the effect of extension tubes on bronchodilatation in asthmatic patients have given conflicting results, owing to differences in size and shape of extension tubes, inhaler technique, and number of inhalations from the extension tube. Lindgren et al found that the PET increased bronchodilatation when the technique of inhalation was not specified, ${ }^{10}$ but not when optimal inhaler
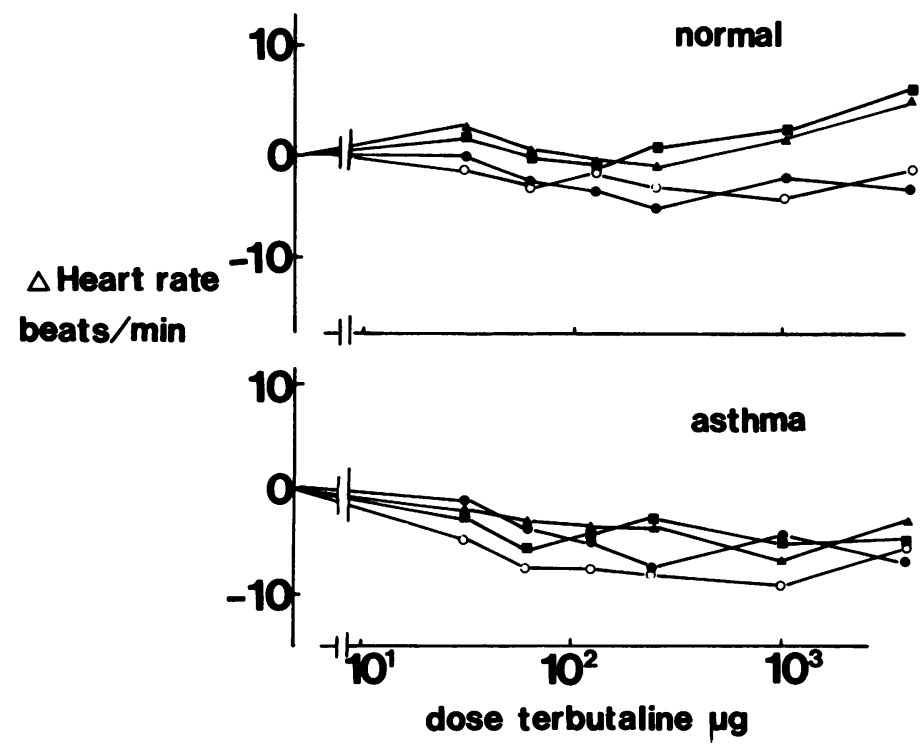

Fig 4 Heart rate response to the four techniques of inhalation in normal and asthmatic subjects. Each point represents the mean change in heart rate from baseline for eight subjects. Symbols as in figs $1-3$. 
technique was ensured by controlled actuation. ${ }^{11} \mathrm{~A}$ single dose of terbutaline given by PET caused a slightly larger increase in $\mathrm{FEV}_{1}$ than the same dose given by MDI. ${ }^{12}$ Other workers found no difference between the PET and the Acorn nebuliser. ${ }^{13}$ In our study subjects took two inhalations from the PET a suggested by Moren, ${ }^{6}$ and with this technique the PET produced greater bronchodilatation than either the MDI or the nebuliser in both groups. Serum terbutaline concentrations after the PET were similar to those after the MDI in the normal subjects, but lower in the asthmatic subjects. The reason for this is not clear but it may explain the lower incidence of side effects in asthmatic subjects using the PET in an earlier study. ${ }^{11}$

Previous studies comparing inhalation by MDI and nebuliser have used different doses of beta agonist: 200 or $400 \mu \mathrm{g}$ salbutamol by MDI compared with 5 or $10 \mathrm{mg}$ by nebuliser. ${ }^{14-16}$ Bronchodilatation was usually greater with nebulised salbutamol but the differences were small and other studies suggest that it may have been due to the large disparity in dose. ${ }^{17}$ Single dose studies do not allow the efficiency of techniques to be compared, particularly when the doses are close to the top of the dose response curve.

The amount of drug which enters the lung from a nebuliser depends on the type of nebuliser and the way in which it is used. Values as low as $1 \%$ have been recorded, ${ }^{18}$ though with the Inspiron Mini$\mathrm{Neb}$, used as in this study, $12 \%$ of the dose leaving the nebuliser was found to enter the lungs. ${ }^{19}$ With an MDI $8.8 \%$ is deposited in the lungs. ${ }^{4}$ The main difference between the two techniques is that most of the dose from the nebuliser is exhaled or left in the apparatus (87\%); only $1 \%$ is deposited in the mouth and oropharyn $x^{19}$ compared with $80 \%$ of the dose from the MDI. In clinical practice nebulisers are usually allowed to run to dryness, when a residual volume of $0.7-1.0 \mathrm{ml}$ remains in the container. ${ }^{20}$ The dose in this study, calculated as the dose leaving the nebuliser by change in weight, will therefore overestimate the response to be expected from the same dose in clinical practice, the exact relationship between the two doses depending on the residual volume of the nebuliser and the technique used to nebulise the drug.

In normal subjects the MDI produced slightly more bronchodilatation than the nebuliser, while in the asthmatic patients it produced a smaller response when this was measured as $\mathrm{FEV}_{1}$; there was no difference between the techniques when response was measured as sGaw. Some of the differences between the two groups could be due to inhaler technique. The asthmatic subjects used their normal technique, showing varying degrees of expertise; all the normal subjects had an adequate technique and this, plus the increased volume of inspiration and absence of airway obstruction, is likely to have produced greater peripheral deposition of drug. Our results agree with those of ChooKang and Grant, ${ }^{14}$ which suggested that the nebuliser might show increasing benefit over the MDI as airway obstruction increases. The lower serum terbutaline concentrations after use of the nebuliser in both groups than after the MDI is probably due to a combination of a greater drug absorption from the lung with the deep inspiration after actuation of the MDI and the larger swallowed fraction.

For patients with severe airways obstruction requiring high doses of beta agonists the nebuliser would appear to offer the same amount of bronchodilatation as the MDI but with lower serum drug concentrations, making potential side effects less likely. The PET, however, produced greater bronchodilatation than either of the other two methods, with low terbutaline blood concentrations similar to those produced by the nebuliser in patients with airways obstruction. It should therefore have a place in the treatment of patients with severe chronic asthma currently taking large doses of beta agonist by nebuliser, since it produces the same benefit from a smaller dose of beta agonists more cheaply and conveniently. It is not necessary for most asthmatic patients, who achieve near maximal bronchodilatation with an MDI alone, though it should be of use for less coordinated patients.

We are very grateful to Dr JG Leferink for measuring serum terbutaline concentrations, Astra Pharmaceuticals for financial support for the study, and Mrs M Dowling for typing the manuscript.

\section{References}

${ }^{1}$ Thiringer G, Svedmyr N. Comparison of infused and inhaled terbutaline in patients with asthma. Scand $J$ Respir Dis 1976;57:17-24.

${ }^{2}$ Larsson S, Svedmyr N. Bronchodilating effects and side effects of beta- 2 adrenoceptor stimulants by different modes of administration (tablets, metered aerosol and combinations thereof). Am Rev Respir Dis 1977;116:861-9.

${ }^{3}$ Davies DS. Pharmacokinetics of inhaled substances. Postgrad Med J 1975;51, suppl 7: 69-75.

${ }^{4}$ Newman SP, Pavia D, Moren F, Sheahan NF, Clarke SW. Deposition of pressurised aerosols by asthmatic patients. Thorax 1981;36:52-5

${ }^{5}$ Paterson IC, Crompton GK. Use of pressurised aerosols by asthmatic patients. $\mathrm{Br}$ Med J 1976;i:76-7.

${ }^{6}$ Moren F. Drug deposition of pressurised inhalation aerosols. Influence of actuator tube design. Int $J$ Pharmacol 1978;i:205-12. 
${ }^{7}$ Newman SP, Moren F, Pavia D, Little F, Clarke SW. Deposition of pressurised suspension aerosols inhaled through extension devices. Am Rev Respir Dis $1981 ; 124: 317-20$.

${ }^{8}$ Connellan SJ, Wilson RSE. Nebulised salbutamol in adult asthma. Lancet 1978;i:662-3.

${ }^{9}$ Leferink JG, Wagemaker-Engels I, Maes RAA, Lamont H, Pauwels R, Van der Straeten M. Quantitative analysis of terbutaline in serum and urine at therapeutic levels using gas chromatography-mass spectrometry. J Chromatography 1977;143:299-305.

${ }^{10}$ Lindgren SB, Formgren H, Moren F. Improved aerosol therapy of asthma: effect of actuator tube size on drug availability. Eur J Respir Dis 1980;61:56-61.

" Lingren SB, Larsson S. Inhalation of terbutaline sulphate through a conventional actuator or a pearshaped tube: effects and side-effects. Eur J Respir Dis 1982;63:504-9.

${ }^{12}$ Lulling J, Delwiche JP, Hidinger K-G, Prignot J. Influence of different extension-actuator tubes on the bronchodilation of a terbutaline sulfate aerosol. Eur J Respir Dis 1983;64:33-7.

${ }^{13}$ O'Reilly JF, Buchanan DR, Sudlow MF. Pressurised aerosol with conical spacer is an effective alternative to nebuliser in chronic stable asthma. $\mathrm{Br} \mathrm{Med} J$
1983;286:1548.

${ }^{14}$ Choo-Kang YFJ, Grant IWB. Comparison of two methods of administering bronchodilator aerosol to asthmatic patients. Br Med J 1975;i:119-20.

${ }^{15}$ Cayton RM, Webber B, Paterson JW, Clark TJH. A comparison of salbutamol given by pressure packed aerosol or nebulisation via IPPB in acute asthma. Br J Dis Chest 1978;72:222-4.

${ }^{16}$ Christensson P, Arborelius M, Lilja B. Salbutamol inhalation in chronic asthma bronchiale: dose aerosol vs jet nebuliser. Chest 1981;79:416-9.

17 Tarala RA, Madsen BW, Paterson JW. Comparative efficacy of salbutamol by pressurised aerosol and wet nebuliser in acute asthma. Br J Clin Pharmacol 1980;10:393-7.

${ }^{18}$ Asmundsson T, Johnson RF, Kilburn KH, Goodrich JK. Efficiency of nebulisers for depositing saline in human lung. Am Rev Respir Dis 1973;108:506-12.

${ }^{19}$ Lewis RA, Cushley MJ, Fleming JS, Tattersfield AE. Is a nebuliser less efficient than a metered dose inhaler and do pear-shaped extension tubes work? Am Rev Respir Dis 1982;125:94.

${ }^{20}$ Stainforth JN, Lewis RA, Tattersfield AE. Dosage and delivery of nebulised beta-agonists in hospital. Thorax 1983;38:750-3. 